\title{
Advantages and Disadvantages of a Cashless System in Thailand during the COVID-19 Pandemic
}

\author{
Somkid YAKEAN ${ }^{1}$ \\ Received: September 01, 2020 Revised: October 26, 2020 Accepted: November 05, 2020
}

\begin{abstract}
At present, the payment system in Thailand changes from a paper-based system to a cashless payment system. A coin has its two sides, so the cashless payment has its advantages and disadvantages. This article describes the general advantages and disadvantages of a cashless society in Thailand in the COVID-19 situation. The cashless payment in Thailand consists of credit cards, automated teller machines, direct debit, mobile/Internet banking, e-Wallet, PromptPay, and QR code. The cashless payment is able to assist the government for tax collection accuracy and facilitates users to make financial transactions more transparent and efficient. In addition, the cashless system provides benefits to businesses in which they are able to increase sales and expand business by providing convenient, safe and faster services to customers in making payment for goods/services. It assists businesses to save time and cost of cash management and reduce the paperwork. The cashless payment made the life of students, housewives, and elderly people very easy to carry out financial transactions and there is no need to meet the financial institution staff. This payment system needs advanced technology system skills, a smartphone, and a technology facility. Finally, the cashless payment can reduce the spreading of COVID-19.
\end{abstract}

Keywords: Cashless, E-Payment, Advantages, Disadvantages

JEL Classification Code: D9, E42, F65

\section{Introduction}

The electronic payment (e-payment) system is known as a cashless payment system. The content of a cashless payment system is usually some form of digital financial instruments or credit cards that are backed by banks or nonbanks. Cashless payment is financial transactions executed online between buyers and sellers. This payment system helps companies to do businesses with a low cost of financial transactions. It provides benefits to all types of businesses; for small businesses, this payment system assists them to increase sales by providing convenience to customers to pay for goods or services and to expand business reach towards online customers who visit their web pages, so they are able

${ }^{1}$ First Author and Corresponding Author. Lecturer, Finance and Banking Department, School of Business and Communication Arts, University of Phayao, Phayao, Thailand [Postal Address: 19, Moo 2, Tambon Maeka, Amphur Muang, Phayao, 56000, Thailand]

Email: audyken@gmail.com

(c) Copyright: The Author(s)

This is an Open Access article distributed under the terms of the Creative Commons Attribution Non-Commercial License (https://creativecommons.org/licenses/by-nc/4.0/) which permits unrestricted non-commercial use, distribution, and reproduction in any medium, provided the original work is properly cited. to send discounts coupons and promotions campaigns to their customers directly. For large businesses, this payment system helps them to increase sales by understanding their customers' preferences from e-payment data. Then, they can use e-payment data to set up prices and promotions campaigns for customers as well as loyalty programs. Moreover, e-payment helps users to conduct financial transactions more efficiently and accurately.

At present, people around the world have been affected by the COVID-19 pandemic. The coronavirus can spread to people in close contact via small droplets produced by coughing, sneezing, and talking. When people get in contact with cash or cheque from people infected, Covid19. They might get infected themselves. This article aims to describe the general advantages and disadvantages of a cashless society in Thailand in the COVID-19 situation.

\section{Information of Cashless in Thailand}

\subsection{Background of Cashless in Thailand}

The e-payment system in Thailand is known as a cashless payment system. This payment system is an advanced technology system. The e-payment system in 
Thailand comprises a credit card, automated teller machine (ATM), direct debit, mobile banking/Internet banking, e-Wallet, PromptPay, and Quick Response (QR Code). The credit card is issued by banks or non-bank institutions, allowing the cardholders to make purchases or payments on credit and repay later. The ATM allows cardholders to withdraw cash, transfer funds, and check the balance at the machines. Moreover, this payment system allows customers with cards issued by overseas banks and other financial institutions to do transactions in other countries. A debit card is a payment system for goods and services such as payment of utility bills. Most debit cardholders prefer to use cards for paying utility bills as payments are directly deducted from their bank account. Mobile banking is also known as Internet banking. This payment system allows customers to execute financial transactions through a smartphone or a tablet. So, this payment system can support e-commerce businesses with convenience, and increases the growth of e-commerce. E-Wallet is used for financial transactions that make payments through a smartphone or a tablet. e-Wallet users need an e-Wallet ID to safely make financial transactions.

The e-Wallet ID refers to the 15-digit electronic wallet identification number that customers receive when services providers complete the Know Your Client (KYC) process. The values of e-Wallet depend on the customer topping up the money in the e-wallet and its record on computer networks. It helps customers to make payment more conveniently and quicker for everyday spending, at a lower fee. The PromptPay is an e-payment that was initially launched by the government to disburse government welfare payments. This payment system has enabled faster and more convenient financial transactions among individuals and businesses by using National ID numbers or mobile phone numbers as a proxy for traditional bank account numbers. Transferring money fees via the PromptPay range from THB 0 to 10 , which is very low. The Thai standard QR Code is a standard for financial transactions that allow businesses to accept payments directly into their bank accounts without having to invest in an electronic data capture (EDC). It is more convenient for small businesses and public transportation service providers to receive money at the point of service/sales. The users won't need to scan different QR codes when executing payments for services/goods, while business owners only have to display one QR code for receiving payments. This payment system only needs a smartphone or a tablet and a PromptPay account to make payments. As mentioned above, all kinds of payment systems do not contact money or cheque. Thus, this will reduce the spread of COVID-19.

\subsection{Benefits of Cashless System}

The growth of e-commerce can boost the use of e-payment because this payment system can enable purchases of goods in a more convenient, faster, and safer way. In Thailand, e-payment provides the benefits for e-commerce businesses to compete and boost sales. Moreover, e-payment will enable the creation of a financial database of SMEs and customers. The financial institutions or non-financial institutions are able to use the information to develop credit scoring for approving loans. They are also able to use data to provide services for private wealth management and insurances. It also improves financial services among customers and businesses because they are able to access the information to support their needs. Moreover, this payment system is able to support the growth of SMEs to develop the products and the government to design appropriate and effective policies.

E-payment helps businesses to save time over cash transactions and cash management costs like employee cost, cash monitoring cost, and guarding cash cost. Moreover, e-payment is the most powerful weapon against corruption, deforestation, and illiterate person. The financial transactions of e-payment can be executed by the online system at home without carrying real currency or need for pen, paper, and a physical appearance anywhere. This payment system also has made the life of students, housewives, and elderly people with smartphones, tablets, or smartwatch to do financial transactions very easily. This payment system can also help the government to increase tax because the government is able to track all financial transactions of businesses. Finally, this payment system is able to reduce the spread of COVID-19 as people are not in contact with cash or cheques.

\section{Research Methodology}

\subsection{Data of Payment System in Thailand}

Figures 1 and 2 show the volume and value of e-payment in Thailand that most people are willing to use for financial transactions. The Internet/mobile banking, PromptPay, and e-Wallet are popularized among Thai people to use for their financial transactions. Most people use the Internet/ mobile banking for e-commerce business because this payment system is convenient and involves lower fees. They can execute financial transactions anywhere with an Internet connection. Most people rely on PromptPay, because they registered numbers adopted for government welfare payment, government transfers, and tax refund. Moreover, most people use PromptPay for daily low-value funds transfers and payments. This is due to the convenience of funds transfer, where a fee of financial transaction is exempted for the fund transfer of THB 5,000 or less, and the number of transfers allowed per day is unlimited.

\subsection{Source of Data}

This article obtained the data from the Bank of Thailand (BOT) and online. 


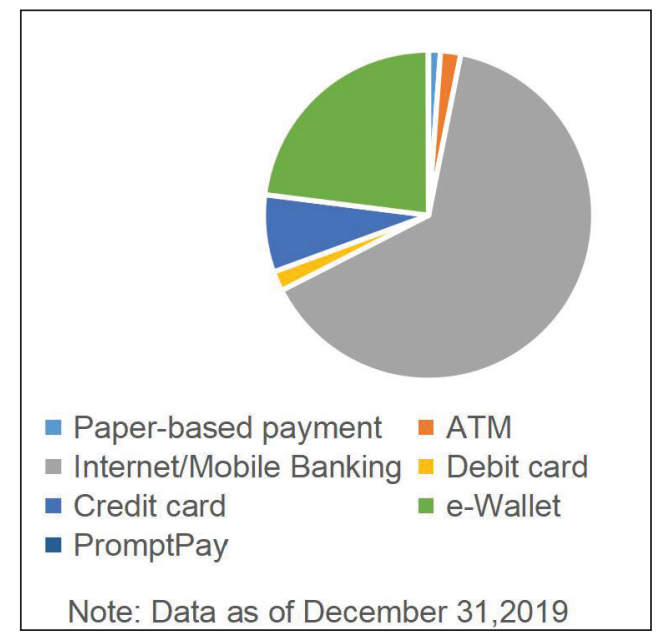

Figure 1: Volume of Payment Transactions

\section{Summary Advantages and Disadvantages of Cashless}

A coin has its two sides, so the cashless payment system has its advantages and disadvantages. The following are the advantages and disadvantages of a cashless society.

\subsection{Advantages of Cashless System}

Cashless initiatives in Thailand such as PromptPay, QR code, e-Wallet, and multifunctional payment cards can benefit businesses in numerous ways and can reduce the spread of COVID-19. Below is a description of the advantages of a cashless society.

1. A cashless society is able to reduce corruption because financial transactions are more transparency in the system and everywhere.

2. Financial transactions can be made while sitting at home or anywhere instead of going to the bank staff and deal with staff to get cash.

3. Documentation for funds transfer can be reduced because transactions are kept in computer networks.

4. It is able to continuously communicate with the user and provide additional, personalized information.

5. The service providers are able to offer special discounts and gifts to users via the e-Wallet. This service will help users to make better purchase decisions.

6. It is able to reduce the hidden cash management costs such as logistics cost, storage cost, and production cost.

7. It helps the government to collect tax accurately because financial transactions are mostly made through a system and data are kept in computer networks. This system is able to help the government officers to track irregularities in financial transactions.

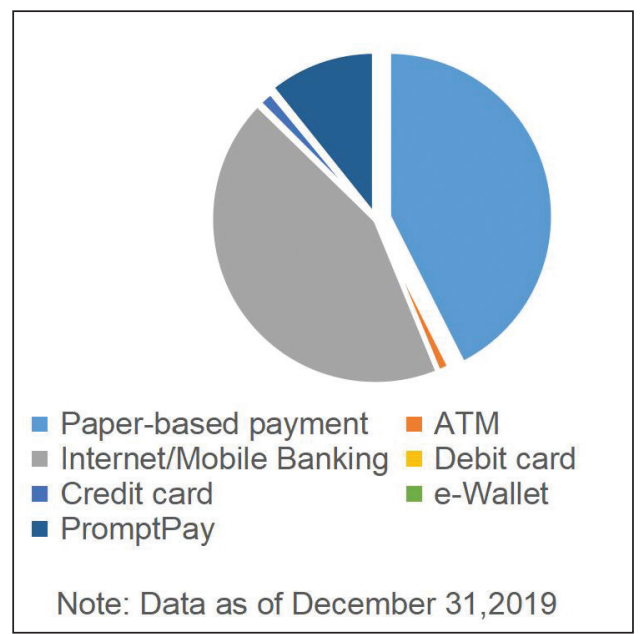

Figure 2: Value of Payment Transactions

8. It is able to reduce crime because there is no cash to steal.

9. There is less money laundering because this payment system executes financial transactions through the online system.

10. It saves time and cash management costs because the transactions are mostly keep on the computer networks.

11. It helps to easily currency exchange while traveling internationally.

12. It helps people to withdraw a small amount of money and to transfer to the bank's account without going to the banks.

13. It is able to help people which they are able to pay utility bills such as electricity bills, water bills, etc. without going to the office. This e-payment is able to help to reduce the epidemic of Covic19 in the world.

14. It is giving away an increasing amount of information (data) about users living and spending habits.

15. It helps people easily make cash budget due to having financial transaction data.

\subsection{Disadvantages of Cashless System}

As Thailand moves to a cashless society, people should be aware of the disadvantages of a cashless system.

1. E-payment applications like PromptPay, QR code, or e-Wallet cannot execute payment without working with a smartphone or tablet. Thus, most people must have to carry a backup in the form of cash or a debit or credit card.

2 . It increases the ability for cybercriminals to infiltrate the e-payment system.

3. It is possible to access or shut down e-Wallets or mobile banking remotely. Thus, the hacker can break into people's financial accounts. 
4. Many villagers do not have a smartphone or tablet. Thus, they cannot make financial transactions through e-payment applications like QR code, PromptPay, or e-Wallet.

5. Some people lack knowledge of technology, so they are afraid to use a cashless system and prefer the old ways of cash transactions.

6. The e-payment system requires customers to divulge their personal information, thus, payment may lead to a possible data breach.

7. The poor and people without bank account will have difficulty paying and receiving payments.

8. This payment system means less privacy. People have to trust the organizations that handle their data, and they might have nothing to hide, but their payment information could turn up in ways that are impossible to predict.

9. The poor people don't have smartphones or tablets to execute financial transactions. Thus, they have no way to get paid or receive aid.

\section{Conclusion}

People around the world have been affecting by the COVID-19 pandemic, but the e-payment system is able to reduce the spread of the virus as e-payment is contactless. The e-payment system has advantages and disadvantages; it is able to help the government to collect taxes more accurately. The e-payment can assist users to make financial transactions more transparently and efficiently. But users need to have technology skills, a smartphone, and a technology facility. Thailand should promote e-payment and how easy it is to use it; it will help save time as well as hardship. The e-payment system will reduce the spread of COVID-19 epidemic.
The public also should be educated on the advantages and disadvantages of a cashless society. The government and private sector should promote the e-payment system, such as PromptPay, QR code, and e-Wallet.

\section{References}

Bank of Thailand. (2019). Oversight of Payment System. Retrieved May 1, 2020, from https://www.bot.or.th/English/ PaymentSystems/OversightOfPaymentSystems/Pages/default. aspx

Bank of Thailand. (2020). Payment System Roadmap No.4 (2019-2021). Retrieved May 1, 2020, from https://www. bot.or.th/English/PaymentSystems/PolicyPS/Documents/ PaymentRoadmap_2021.pdf

Bank of Thailand. (2018). Payment System: Standardized QR Code in Thailand. May 1, 2020, from https://www.bot.or.th/Thai/ AboutBOT/Activities/event/Documents/ADBI_bancha.pdf

Bank of Thailand. (2016). PromptPay Ready to Use. Retrieved May 1, 2020, from https:/www.bot.or.th/Thai/PaymentSystems/ PSServices/PromptPay/Pages/default.aspx

Bank of Thailand. (2020). Payment Transactions. Retrieved May 1, 2020, from https:/www.bot.or.th/English/Statistics/ PaymentSystems/Pages/StatPaymentTransactions.aspx

Pimnipa, B. (2017). Why $s$ is Essential to Merchant as Thailand becomes a Cashless Society. Retrieved May 1, 2020, from https://www.scb.co.th/en/personal-banking/stories/are-youready-with-virtual-money.html

Sivasakthi, N. R. \& Nandhini, M. (2017). Cashless Transaction: Modes, Advantages and Disadvantages. International Journal of Applied Research, 3(1), 122-125. 